\title{
LA CULTURA DE LA RESISTENCIA JUVENIL Y EL PROCESO EMANCIPADOR
}

\author{
Hugo E. Biagini ${ }^{1}$ \\ CONICET-Argentina \\ Grupo de Investigacion-HISULA-SHELA \\ bbiagini@mail.retina.ar
}

Recepción: 30/05/2008

Evaluación 01/06-15/09/2008

Aceptación: 29/09/2008

Artículo de Revisión

¡Desgraciado el pueblo donde los jóvenes son humildes con el tirano, donde los estudiantes no hacen temblar el mundo! Juan Montalvo

\section{RESUMEN}

Se sintetiza en el papel el protagonismo de la juventud latinoamericana durante la independencia, el movimiento reformista de Córdoba y en las vísperas del bicentenario a través del complejo fenómeno de la altermundialización. A través de posiciones disidentes y remisas al principio de autoridad, aquéllos han exigido la modernización de la enseñanza y el acceso a los adelantos científicos, junto a la apertura de la universidad al pueblo y la sociedad.

Palabras Claves: Independencia, movimiento estudiantil, Reforma Universitaria, alterglobalización.

\footnotetext{
${ }^{1}$ Doctor en filosofía, Investigador Principal de CONICET- Argentina. Autor de libros y artículos sobre el problema universitario y movimientos estudiantiles. Coordinó con A-Roig el Diccionario del pensamiento alternativo, que lleva tres tomos editados en Buenos Aires.
} 


\title{
THE RESISTANCE CULTURE IN LATIN AMERICAN STUDENTS: $1810-2010$
}

\author{
Hugo E. Biagini \\ CONICET-ARGENTINA \\ Grupo de Investigacion HISULA-SHELA \\ bbiagini@mail.retina.ar
}

\begin{abstract}
This paper deals with Latin American youth and its special protagonism in three different stages: South American Independence, Cordoba's reformist movement and the alterglobalisation phenomenon of today. Adopting dissident attitudes and against authoritative principles, those students struggled for modern teaching, scientific advances and the opening of university to people and society.
\end{abstract}

Key Words: Independence, alterglobalisation, university, Cordoba's reformist movement

\section{INTRODUCCIÓN}

Se traza aquí un panorama sobre la función protagónica que ha desempeñado la juventud latinoamericana en diversos momentos culminantes, sin excluir la situación actual ni sus perspectivas futuras. Los períodos escogidos comprenden, fundamentalmente, el ciclo de nuestra primera independencia, los inicios del movimiento reformista organizado y la impronta identitaria que se ha ido revelando durante las vísperas del bicentenario.

De tal manera, el ser joven e idealista, ha llegado a plantearse como un vínculo indisoluble. Resultan filiaciones muy caras a la tradición liberadora de nuestra América el poder superar las barreras cronológicas y asociar al joven con el desafío que implica la adopción de grandes finalidades y su puesta en marcha, de tomar partido, sumarse a los desposeídos y bregar contra la injusticia. Bajo esa acepción pudo afirmarse, por ejemplo, la aparente paradoja de que hay jóvenes viejos así como existen ancianos juveniles.

Más específicamente, se acotarán tres secuencias donde los jóvenes, secundarios y universitarios en especial, han implementado modalidades contrahegemónicas. Las etapas en cuestión se hallan delimitadas por la gesta emancipadora, por el grito de Córdoba y por las orientaciones emergentes en nuestros días a través del complejo fenómeno de la altermundialización. 
Las postulaciones solidarias han sido alentadas durante los albores de las revoluciones decimonónicas y fueron instrumentadas ulteriormente por los estudiantes latinoamericanos. A través de posiciones disidentes y remisas al principio de autoridad, aquéllos han exigido la modernización de la enseñanza y el acceso a los adelantos científicos, junto a la apertura de una universidad entreverada con el pueblo y la sociedad. ${ }^{2}$

Sosteniendo una concepción sobre la universidad pública netamente original, nuestro alumnado, tras muchos desvelos y padecimientos, ha visto a su casa de estudios como síntesis superior de dos modelos en pugna —el profesional y el científico-, que aúna los contenidos esenciales de una exclaustración comprometida: crítica al poder, extensión civil de servicios y defensa de los intereses populares. En resumidas cuentas, una universidad que, sin dejar de tender hacia la más alta excelencia académica, se dedique a encauzar el desarrollo integral. Por otro lado, esa misma muchachada, junto a otros sectores civiles, ha participado decididamente en los embates contra el colonialismo, el imperialismo, la oligarquía, las dictaduras militares y el neoliberalismo. ${ }^{3}$

\section{De la Revolución y sus secuelas}

Durante el siglo XIX, numerosos jóvenes impulsaron las sociedades secretas y los movimientos revolucionarios en Europa y América, aunque recién con la centuria posterior se va poder hablar, stricto sensu, del siglo de la juventud. Se trata de un proceso multisecular que corre paralelo a la desmitificación de esa inveterada mirada cosificante que sólo tiene en cuenta como par o como prójimo a un determinado tipo humano y justifica tremendas exclusiones basadas en el género (mujer, homosexual), el bío_psiquismo (enfermo, loco, minusválido), la religión (infiel, hereje), la educación (iletrado), la economía (pobre, trabajador manual), las etnias (no blanco), la política (opositor), la población (mayoríasminorías, nativo — extranjero), la edad (niño, adolescente, joven, anciano). Todo ello representa un vasto complejo coercitivo frente al cual se han levantado esos mismos segmentos discriminados y el estudiantado en particular, como elemento configurativo de lo que han sido los clásicos movimientos sociales autónomos -junto al proletariado y al movimiento cooperativista. ${ }^{4}$

Dentro del actual contexto, cabe destacar la importancia que, para la causa de la emancipación sudamericana, revistió el discurso y la actuación de diversos

${ }^{2}$ BIAGINI, Hugo. (1973): John Locke y la construcción del liberalismo politico, Buenos Aires, EUDEBA.

${ }^{3}$ Como lectura complementaria propia a este trabajo, puede recurrirse a mi capítulo, BIAGINI, Hugo. Roig, AA. (2007): "La fuerza emancipadora estudiantil: de la primera independencia al neoliberalismo", en H.E. Biagini y A. A. Roig, América Latina hacia su segunda independencia. Memoria y autoafirmación, Buenos Aires, Aguilar et al. pp. 245-264.

${ }^{4}$ Ibidem., p. 69. 
estudiantes criollos que tuvieron ocasión de formarse en la Universidad de Chuquisaca y se mostraron permeables a las ideas que iban a confluir en la independencia estadounidense y en la Revolución Francesa; una universidad que, a principios del siglo XIX, había de erigirse en "centro de la conciencia americana" y en una "fuerza renovadora que contribuyó a la estructuración política y social de otros pueblos del continente". En aquella casa de estudios superiores se formaría la pléyade de patriotas que encabezarían los levantamientos contra la dominación hispánica en el Cono Sur, como Bernardo de Monteagudo, José Manuel Rodríguez de Quiroga, Mariano Alejo Álvarez, José Antonio Medina o Jaime de Zudánéz, redactor del Catecismo político cristiano que estaba dirigido a invalidar la jurisdicción española fuera del ámbito peninsular y a sostener la legitimidad de establecer juntas gubernamentales propias en territorio americano:

En las repúblicas, el pueblo es el soberano, el pueblo es el rey, y todo lo que hace lo hace en su beneficio, utilidad y conveniencia; sus delegados, sus diputados o representes mandan a su nombre, le responden de su conductay tienen la autoridad por cierto tiempo. Si no cumplen bien con sus deberes, el pueblo los depone y nombra en su lugar a otros que correspondan mejor a su confianza. ${ }^{7}$

Los catecismos políticos, como los libelos, pasquines y caramillos constituyeron piezas de batalla que invitaban a desencadenar revoluciones al estilo de aquellos conatos que tuvieron lugar en Chuquisaca y La Paz a mediados de 1809 en demanda de autodeterminación. ${ }^{8}$

La filosofía de la Ilustración, trasfondo doctrinario de dichos posicionamientos autonómicos, implicaba la creencia optimista en el valor universal de la razón, el rechazo a las tradiciones y la posibilidad de disolver un pasado oprobioso para crear súbitamente la nacionalidad mediante dispositivos legales, el contrato social, la soberanía popular, la instrucción cívica y las lenguas vivas; factores convergentes para sepultar al antiguo régimen con todas sus miserias y arbitrariedades. ${ }^{9}$ La Iglesia y el cedazo teológico dejan de ser imbuidas como la única fuente del saber, se sustituye sintomáticamente la sotana por el

6 FRANCOVICH, Guillermo. (1948): El pensamiento universitario de Charcas, Sucre, Universidad de San Francisco Xavier. p. 75. MINUTOLO, Cristina. (1987): El rol de la Universidad de San Francisco Xavier de Chuquisaca en la epopeya emancipadora de América, Buenos Aires, Embajada de la República de Bolivia.

7 ROMERO, José Luis. ROMERO, Luis Alberto. (1977): (comps.), Pensamiento político de la emancipación, t. 1, Caracas, Biblioteca Ayacucho, p. 215.

8 Sobre otros usos de esos medios expresivos en otras regiones del continente hacia la misma época, véase SOTO, Diana. (1999): El movimiento de estudiantes y catedráticos en Santa Fe de Bogotá a finales del siglo XVIII, en MARSISKE, Renate. Movimientos estudiantiles en la Historia de América Latina, I, México, UNAM, pp. 40-60.

${ }_{9}$ BIAGINI, Hugo E. (1985): Panorama filosófico argentino, Buenos Aires, EUDEBA. 
traje civil y muchos frailes se inclinan hacia la Independencia —en oposición a la propia postura del papado sobre el particular. ${ }^{10}$

Bajo tales concepciones, entre los tantos ejemplos concernientes al enrolamiento etario e ideológico de los independentistas, suelen citarse pasajes como los siguientes: "el gran Túpac Amaru, fue estudiante en Lima; José Joaquín Olmedo, lee a Voltaire en el Colegio de San Carlos [...] José María Morelos es un alumno revoltoso en el que fructifican las lecciones de Hidalgo; Belgrano a los diecinueve años traduce a Voltaire, Rousseau y Montesquieu; Nariño, joven también, traduce y publica los Derechos del Hombre. Simón Bolívar tiene dieciséis años cuando afirma, ante el virrey de España, que América ha de ser independiente y libre y es este mismo imberbe el que en el Monte Sacro, jura ante su tutor, Simón Rodríguez, libertar a América y afirma ante las dudas de Humboldt, que la revolución ha de crear sus propios líderes". ${ }^{11}$

La creciente conspiración que se vivía en el continente fue pintada en forma literaria:

Los ejércitos del silencio se pasaban las armas; se hacían correrplanes siniestros al amor de la noche. Los estudiantes le regalaban sus domingos a la conspiración. Todas sus horas libres eran para ponerse en contacto con ciertas gentes letradas que leian de contrabando y hacian la oposición desde tertulias secretas y desde ciertas academias que funcionaban bajo la equivoca carátula de especulaciones filosóficas. ${ }^{12}$

Con el advenimiento de la revolución, las sociedades filantrópicas, patrióticas, literarias, filotécnicas y políticas de la juventud cumplieron a su vez una función semejante. La misma enseñanza se orientó en esa dirección, como llegó a ser el caso de la Escuela de Matemáticas, cuyo objetivo general fue transcripto por la Gaceta de Buenos Aires en octubre de 1810: "proporcionar a los jóvenes la instrucción necesaria para sostenerse con brillo en la milicia”. ${ }^{13}$

\footnotetext{
${ }^{10}$ Op. cit., p. 80.

11 AGUIRRE, Manuel Agustín. (1987): La Segunda Reforma Universitaria, Quito, Universidad Central del Ecuador, 1973, pp. 40-41. Cfr. también, del mismo autor, Universidad y movimientos estudiantiles, Quito, Alberto Crespo Escalada, pp. 161-168.

12 ARCINIEGAS, Germán. (1957): El estudiante de la mesa redonda, Buenos Aires, Edhasa, p. 157.

${ }^{13}$ Citado por GONZÁLEZ, Julio V. (1929): en La emancipación de la universidad, Buenos Aires, Talleres Gráficos L. J. Rosso, p. 13. Una muestra de este afán por formar a los jóvenes en el arte bélico puede seguirse a través del periódico conservador lanzado por Felipe Senillosa, quien iba a ser el mismo director de la Academia de Matemáticas. Se trata del mensuario Los amigos de la patria y de la juventud (18'11'1815-mayo 1816), cuya última edición facsimilar ha aparecido en Buenos Aires publicada por la editorial Docencia y la Fundación Hernandarias en 2004. Sobre el contexto político-cultural del período revolucionario, véase BIAGINI, H. E. (2005): El republicanismo en acción, en F. Colom González (ed.), La construcción de las identidades nacionales en el mundo bispánico, vol. 1, Madrid-Frankfurt, Iberoamericana-Vervuert, pp. 131-143.
} 
Con el correr del tiempo, entre los círculos posrevolucionarios más notorios se encuentra la Joven Generación Argentina que promueve Esteban Echeverría en el Río de la Plata con el propósito de incentivar una segunda emancipación, la de carácter mental y cultural. En Juan Bautista Alberdi, uno de los principales exponentes de esa agrupación, también conocida como Asociación de Mayo, ya puede observarse un rasgo que suele atribuírsele a varias generaciones posteriores, es decir, la certeza sobre el papel salvífico de la juventud, cuya misión debe apuntar para Alberdi hacia "todas las grandezas humanas", entre ellas: "la emancipación de la plebe" y la "transmisión de la democracia al Viejo Mundo". ${ }^{14}$

Al filo del Novecientos, el modernismo exaltará la figura del joven, tesoro divino y humano a la vez, frente a la cultura prosaica del buen burgués. En el resonante arielismo de Rodó, la juventud, objeto de auténtica devoción, irrumpe como un mediador entre la utopía y lo real, como sujeto movilizador por antonomasia de las masas y como responsable por el destino de la ciencia, de los mejores gobiernos y hasta de la unión continental; una mística juvenilista que penetra visceralmente en los movimientos estudiantiles y se extiende hasta llegar a nuestros días. ${ }^{15}$ Concomitantemente, hacia fines de siglo, los estudiantes guatemaltecos propician una sostenida resistencia contra las dictaduras y el imperialismo a través de lo que han denominado como la huelga de Dolores y su órgano periodístico No nos tientes, cuyas variantes se han prolongado asimismo hasta la actualidad. ${ }^{16}$

Es la época en la cual comienzan a organizarse las primeras federaciones regionales y los congresos continentales de estudiantes, los cuales, más allá de sus resabios retardatarios, nos legarán un vasto repertorio que testimonia la potencialidad reflexiva de aquella juventud universitaria e insinúa respuestas alternativas a los modelos dominantes en el ejercicio del poder, enarbolando las categorías del sueño y la rebeldía como máximas expresiones de la realidad. ${ }^{17}$

14 J. B. Alberdi. (1984): Fragmento preliminar al estudio del derecho, B. Aires, Biblos, pp. 148-149. Otras referencias sobre antecedentes de la literatura juvenilista rioplatense en ROIG, Arturo. (1998): Dedoro Roca y el movimiento de la Reforma de 1918, en su libro La universidad hacia la democracia, Mendoza, EDIUNC, pp. 132-133, 157-158.

${ }^{15}$ Sobre "arielismo" y "juvenilismo", ver las entradas respectivas en BIAGINI, H. y ROIG, A. (2008) Diccionario del pensamiento alternativo, Buenos Aires, Biblos, pp. 50-52 y 313-316.

${ }_{17}^{16}$ BARNOYA GARCÍA, José. (1979): Historia de la Huelga de Dolores, Guatemala.

BIAGINI, Hugo E. Historia ideológica y poder social, Buenos Aires, Centro Editor de América Latina. 


\section{El otro centenario: la brecha reformista}

Frente a los festejos y pompas oficiales, que celebran ruidosamente el primer centenario de la patria - entre persecuciones al proletariado y a los movimientos populares - se alza el grito emblemático proferido en Córdoba hacia junio de 1918, el cual, si bien cuenta con significativas prelaciones como las ya mentadas sobre la contracultura finisecular y sobre el ciclo de congresos estudiantiles lanzado en Montevideo un decenio atrás—, viene a inaugurar un nuevo panorama dentro del escenario continental. Desde la óptica de diversas rupturas y aperturas institucionales tanto mundiales como regionales, junto con el auge de un sindicalismo combativo y el surgimiento de los partidos comunistas, se arribó a la convicción de que a Sudamérica le tocaba pasar por un estadio sustancialmente inédito, por una hora sublime de innovación y libertad, al estilo de lo que aparece expuesto en la literatura programática del célebre Manifiesto Liminar de los jóvenes reformistas. ${ }^{18}$

Dicha impronta contestataria no sólo emana del accionar y de la letra de socorridos documentos fundacionales. Cuando hace eclosión el movimiento reformista en Córdoba, sale allí un libro echado en el olvido pese a su alta simbología conceptual, Reflexiones sobre el ideal político de América, publicado por uno de los principales referentes teóricos de ese movimiento: Saúl Taborda, en cuyo texto puede explicitarse el resonante vaticinio del manifiesto de 1918 acerca del advenimiento de una hora americana. En esa obra, Taborda avanza sobre las trilladas expresiones metafóricas acerca del Nuevo Continente como tierra promisoria, sol de primavera o Atlántida encantada. A la voz persistente de "América, jla hora!", el pensador cordobés estimaba que había llegado el momento de romper el yugo factoril con Europa y acceder a una verdadera libertad - tras un siglo de pseudoindependencia. Según él, estaban dadas las condiciones para sobrepasar la mera democracia electoralista, al servicio de una clase parasitaria y de un sistema en el cual los partidos poseen un mínimo de soberanía y un máximo de autoridad. Una genuina democracia americana debía basarse en el imperio de la opinión pública y social, en un estado cooperativo donde se entone el himno de la solidaridad, desaparezca el analfabetismo, se cuestionen los medios de servidumbre y la tierra no resulte objeto de apropiación privada. Para viabilizar tales objetivos tenía que socializarse la industria, la banca y el transporte mediante un dictamen que expropia en beneficio de los pueblos. Toda una plataforma maximalista que dista de poseer la tónica pequeño-burguesa que les fuera asignada prejuiciosamente a los primeros reformistas argentinos. ${ }^{19}$

\footnotetext{
${ }^{18}$ Entre los innumerables sitios donde se reproduce dicho manifiesto ad integrum, puede verse mi antología: ROCA, Deodoro. (2006): Reformismo y antiimperialismo, Buenos Aires, Grupo Editor Universitario, pp. 27-31.

${ }^{19}$ TABORDA S. (2007): Reflexiones sobre el ideal politico de América, 2da. edición, Buenos Aires, CECIES y GEU.
} 
Otros testimonios originarios de la juventud estudiantil, como los que se traslucieron en Chile repetidamente, han enfatizado la fuerza del ideario y las prácticas en cuestión:

[El] momento actual [...] es elperiodo de transición más interesante porque ha atravesado la bumanidad, momento en que el egoísmo y la bipocresía sociales tendrán que ceder ante el empuje del Derecho [que] irá conquistando las clases desheredadas para alcanzar rápidamente el máximum de su florecimiento en este siglo único que hasta aqui babia irradiado su luz científica, filosófica 0 artística sólo a una minoría bastante reducida. ${ }^{20}$

El programa reformista vino a amalgamarse con el "derecho sagrado a la insurrección” — según rezaba el propio manifiesto liminar-, cuando sonaban cánticos revolucionarios y se entonaba el himno patrio junto a la Internacional. Existía la certidumbre de que no se estaba asistiendo a simples chispazos de rebeldía sino a un batallar sin tregua que produciría una honda transformación hasta acabar con la "bestia interior" que continuaba gobernando al mundo. La apuesta por la revolución implicaba a su vez la crisis de un viejo axioma: el de la evolución individual y social. Pasó a cobrar relieve entonces la acción directa como tal, sin políticos charlatanes ni profesores acomodados; la necesidad de sustituir los parlamentos por tribunas públicas; la creencia en una única fuerza capaz de combatir las instituciones represivas: el movimiento revolucionario de las clases oprimidas, mundialmente organizadas con el apoyo de los intelectuales. ${ }^{21}$

El mismo origen del derecho de propiedad — sostén de un ordenamiento salvaje basado en el propio interés y las ventajas particularesconstituye para el estudiantado reformista un despojo riguroso legislado por los mismos despojadores. La burguesía y sus exponentes propugnan una imposible armonía entre capital y trabajo, mientras consideran utópico que este último pudiera llevarse a cabo sin estímulos materiales y con el único objeto de satisfacer a la comunidad. Desde tal enfoque, los estudiantes radicalizados aseveraban que el sistema capitalista tenía sus días contados y que debía caer como lo hicieron los regímenes basados en la injusticia, la violencia y la explotación. Aquél sistema sería sustituido por una sociedad centrada en la cooperación productiva; su permanencia implicaba el hecho de que la humanidad no pudiera salir de la miseria y la degradación. ${ }^{22}$

\footnotetext{
${ }^{20}$ VALDÉS V., Carlos. (1918): Evolución y revolución, Juventud (Sgo. de Chile), agosto, p. 60.

${ }^{21}$ BIAGINI, Hugo E. (Compilación). (1993): Redescubriendo un continente. La inteligencia española en el París Americano, Sevilla, Diputación Provincial. p. 70

22 (1995):Intelectuales y politicos españoles a comienzos de la inmigración

masiva, Buenos Aires, Centro Editor de América Latina. p. 90
} 
De ahí la censura a los cobardes que transigen con el sistema, callan cuando les conviene, se arriman al más fuerte, no levantan su voz ante la infamia, mueren inútilmente o retardan la aparición de otro orden distinto de cosas. De ahí el rechazo al arribismo político-estudiantil, a la pequeña burguesía y a la clase media, sectores a los que consideraban, por otra parte, tendientes a desaparecer. De ahí también el respaldo a la revolución rusa, ese "nuevo sol" que les permitía asegurar que "la claridad viene de Oriente". Una "nueva vida", con "nuevos horizontes" que mostraban el fracaso del gradualismo en todo el pasado previo. Según lo sugería un estudiante secundario: “ $¡ U$ Uruguayos, peruanos, argentinos, chilenos y americanos todos! [...] la 'hora de América' [...] es la hora de Rusia y será la hora del mundo". ${ }^{23}$ La experiencia soviética fue reivindicada no sólo porque en ella se procuraron socializar los medios de producción sino por el extraordinario impulso otorgado por los bolcheviques a la instrucción pública y a la eliminación del analfabetismo — como ningún otro gobierno burgués lo había podido lograr. Debía apuntarse a la formación de un soviet de estudiantes. Por eso la siguiente exhortación:

\section{Hermano, hazte buen tirador [...] Pon toda tu pasión en el manejo del} arma $[\mathrm{y}]$ oriéntala con un pensamiento libertario. Acuérdate que la revolución social necesita de tu brazo y cuanto más diestro mejor. En la barricada de mañana, es preciso que cada disparo sea un blanco [...] Mira a Rusia y aprovecha la lección. ${ }^{24}$

Sin embargo, aun dentro de las vertientes izquierdistas, otro sector objetó la dictadura del Partido Comunista y la postración del pueblo ruso, la falta de autonomía sindical, los privilegios que imperaban dentro de la enseñanza y la desatención infantil, equiparando al militarismo rojo con la Iglesia y el zar. Sí se mantenía, en cambio, bastante incólume el múltiple rol atribuido a la juventud: como juez imparcial para determinar los cambios sociales, como mediador entre pudientes y sumergidos, como oponente a los prejuicios y a la falsedad, como encarnación del espíritu de perfeccionamiento y de sacrificio según lo ilustran estos versos:

\section{Jwentud sembradora, ruda mano morena, tú darás tu sudory tu sangre y tu vida y por ti la cosecha será más firme y buena y aquietará su angustia la tierra conmovida. ${ }^{25}$}

Finalmente, las brevas parecieron maduras para desembarazarse de las explicaciones etnocéntricas y del propio juvenilismo:

${ }^{23}$ RUBENS, Marcelo. Claridad (S. De Chile), 14-2-1921, p. 4.

24 Nalo, ibid.,22-1-1921, p. 5.

25 MEZA FUENTES, R. (1920): Elogio de las fiestas de la primavera, Juventud, primavera, p. 1. 
Interpretar el latinoamericanismo reformista como un conflicto de razas - latino y sajona — sería el colmo de la puerilidad. La unica interpretación posible es la de posición de lucha frente al capitalismo agresivo, sea yanqui o de cualquier parte, personifiquese en Mr. [¿Charles Evans?] Hugues, en Mussolini o en el de [Primo de] Rivera. ${ }^{26}$

\section{Al lado del obrero: he abí el lugar del verdadero reformista. ${ }^{27}$}

Entre los espacios comunes propios del binomio estipulado - junto con la calle, los locales corporativos y los medios de lucha-, se encuentra un verdadero puente de la unión obrero—estudiantil: aquél que tendieron las universidades populares, abiertas contra viento y marea por el estudiantado latinoamericano en distintos países del continente, cumplimentando la meta asignada por sus mentores, como Manuel González Prada, a esas casas de estudio: "crear un 'frente único de trabajadores manuales e intelectuales' que asegurara la alianza del intelectual con el obrero". ${ }^{28}$ Uno de los artífices de esos emprendimientos educativos, el dirigente reformista cubano Julio Antonio Mella, no dejaría de reconocer, aún en medio de una situación súmamente desfavorable, "que nada más útil se ha hecho en la América en el campo de acción de la cultura, que estas 'revoluciones universitarias'. Sin ellas, ¿qué esperanza había para el porvenir? ${ }^{29}$

Aquél "lugar" vanguardista también será compartido por el proletario con otro sujeto social, el indio - "el más horrible dolor del mundo", olvidado por las burocracias de Lima y La Paz, aliadas con los explotadores; habida cuenta de que dicha independencia política sólo fue usufructuada por los criollos y el indígena prosiguió viviendo en condiciones feudales, según puntualizaba la federación de estudiantes peruanos a sus cofrades bolivianos, durante el centenario de la independencia de éstos de España. ${ }^{30}$

Raúl Haya de la Torre, inventor de la gráfica terminología Indoamérica, traería poco más tarde a colación, desde el destierro, que en 1920 durante el

${ }^{26}$ LANUZA, José Luis. (1926): La universidad y el pueblo, en DEL MAZO, G. (comp.) La Reforma Universitaria, Buenos Aires, FUBA, tomo I, p. 126.

${ }^{27}$ HURTADO DE MENDOZA, H. Carácter económico y valor social de la reforma universitaria, ibid.

${ }^{28}$ Citado por GAMARRA ROMERO, Juan Manuel. (1987): La Reforma Universitaria, Lima, Okura, p. 176. Sobre universidades populares, ver la entrada ad hoc en nuestro citado diccionario ut supra, pp. 537-539.

29 Mella, J.A. (1959): ¿Puede ser un hecho la reforma universitaria?, en AA.VV., La Reforma Universitaria, 1918-1958, Buenos Aires, Federación Universitaria, p. 327.

${ }^{30}$ Ver pieza transcripta por Del Mazo, op.cit., tomo VI, 1927, pp. 163-164, y también "Mensaje de los estudiantes profesores de las Universidades Populares González Prada, desterrados en la Argentina, al Centro de Estudiantes y Obreros de Trujillo", ibid., pp. 164-168. 
Primer Congreso Nacional de Estudiantes Peruanos, por él mismo presidido, se había consensuado como supremo deber generacional "la reivindicación material y espiritual del indígena". ${ }^{31}$

Por su parte, la Federación de Estudiantes de Chile, en un mensaje de confraternidad a sus pares del Perú, al cumplir éstos el centenario de su independencia, les trasmitirá una firme vocación pacifista enfrentada a los ardores beligerantes por ese entonces:

No renegamos de nuestros padres, pero comprendemos que son ellos quienes, ofuscados por el amor de la patria, han cultivado en nosotros el ciego espiritu guerrero [...]

La juventud americana, que tan señaladas pruebas ha dado de su idealismo y de su serenay acertada apreciación de los hechos reales del mundo politico y moral, debe empezar una verdadera e infatigable cruzada por crear el espiritu de paz. en esta bella parte del planeta, que es bastante grande y rica para que todos podamos convivir sin injusticia ni violencia. ${ }^{32}$

El rechazo a las dictaduras, a los terratenientes, al clericalismo, a la carrera armamentista, a los capciosos políticos burgueses y a las falacias diplomáticas también se reitera una y otra vez, por ejemplo, en la correspondencia de los alumnos paraguayos a sus compañeros latinoamericanos cuando condenan la inmolación de nuestra juventud en estériles guerras fronterizas y advierten sobre lo sencillo que resulta "ser héroe en un momento de animal ofuscación". 33

Un hito en la materia lo constituye el congreso internacional de estudiantes que sesionó en un país como México — cuya revolución había llegado a crear puestos de agregados estudiantiles en sus representaciones diplomáticas sudamericanas-, durante las postrimerías de 1921, no sólo para propiciar banderas intrauniversitarias propias de la Reforma como el cogobierno sino también para oponerse a una serie de alienantes tendencias mundanas: tiranías, chovinismo, militarismo, imperialismo, mercantilización del trabajo humano. Junto al núcleo selecto de congresistas que se reunieron en dicha ocasión ${ }^{34}$ en la cual tomó carta de ciudadanía el movimiento reformista organizado-, se rescata un trabajo poco conocido pero que refleja buena parte de las tesis

\footnotetext{
${ }^{31}$ DE LA TORRE, Haya. (1968): El problema del indio, en DEL MAZO, G., La Reforma Universitaria, tomo III, Lima, Universidad Nacional Mayor de San Marcos, pp. $125 \mathrm{ss}$.

${ }^{32}$ Cfr. DEL MAZO, G. (1968): La Reforma Universitaria, tomo III, p. 77.

33 Ibid., pp. 144-146.

${ }^{34}$ Entre ellos, cabe citar algunos nombres de connotada trayectoria, como los de Pedro Henríquez Ureña, Asturias, Vasconcelos, Cosío Villegas, Alfonso Caso, Lombardo Toledano, Orfila Reynal, Porras Barrenechea, Víctor Belaunde, o Heliodoro Valle.
} 
prevalecientes. Apelándose (en versalitas) a la reiterada invocación: "Vivimos una hora solemne" — de gran renovación ideológica y clima revolucionario. Se alude allí al "despertar de la conciencia colectiva" tras la primera guerra mundial, a las descomunales dimensiones que habían cobrado las demandas proletarias, a la caída estrepitosa de un andamiaje social falsamente basado sobre "la desigualdad en el reparto de los bienes", sobre la ignorancia de los pueblos y sobre la obediencia pasiva del joven y el adolescente..$^{35}$

El polígrafo argentino José Ingenieros — junto a José Vasconcelos, Alejandro Korn, Gabriela Mistral y otras figuras precedentes como Valentín Letelier o Manuel González Prada - fue uno de los grandes maestros de la muchachada reformista, entre la cual se encuentran algunos líderes como Haya de la Torre, José Carlos Mariátegui en Perú, Julio Mella en Cuba, Pablo Neruda en Chile, Miguel Ángel Asturias en Guatemala, Germán Arciniegas en Colombia o Carlos Quijano en Uruguay. Sin embargo, Ingenieros recibiría un trato especial, entre otras razones, por su franco apoyo a la revolución rusa ${ }^{36}$ Además, en ese ascendiente generacional de Ingenieros se hallaba en juego un proyecto continental como el de la Unión Latinoamericana, preanunciada por él en un memorable banquete ofrecido a Vasconcelos en Buenos Aires en octubre de 1922. En esa oportunidad, Ingenieros abjura del panamericanismo que, parafraseando la doctrina Monroe, ya había caracterizado como la pretensión de hacer una América para los norteamericanos, mientras alerta sobre un mal correlativo que se iba a acentuar crecientemente y que en nuestros tiempos ya resulta de lesa actualidad: "la hipoteca progresiva de la independencia nacional mediante empréstitos destinados a renovarse y aumentar sin cesar en condiciones cada vez más deprimentes para la soberanía de los aceptantes"37. Años más tarde, el 21 de marzo de 1925, en la misma ciudad porteña se funda dicha gravitante organización que, avalada por miles de estudiantes, reivindica una Reforma Universitaria integral, repudia la penetración capitalista, para propiciar una unificación jurídica, política, económica e intelectual que permitiera salvaguardar la soberanía y la libertad de nuestro continente austral —un emprendimiento similar al hoy naciente UNASUR. Por otra parte, el mismo Ingenieros — como lo iba a hacer Salvador Allende mucho después-, estableció una correspondencia biunívoca entre el ser joven, las izquierdas o la revolución y señaló que la juventud que no se encuadraba con las izquierdas constituía una mera vejez sin canas. ${ }^{38}$

\footnotetext{
${ }^{35}$ DREYZIN, Enrique. (1970): Palabras del delegado argentino, transcritas en Cuaderno de La Plata, [3], julio, pp. 86-91.

${ }^{36}$ Véanse, J. INGENIEROS. (1920): "Los ideales del grupo ¡Claridad”, en Revista de Filosofía, enero y "La reforma educacional en Rusia", ibid., julio.

37 "El discurso de Ingenieros", en A. Palacios, Nuestra América y el imperialismo yanqui (Madrid, Historia Nueva, 1930) p. 8.

${ }^{38}$ Como lecturas adicionales para este apartado sobre el movimiento estudiantil reformista, véanse, inter alia: CIRIA, Alberto y SANGUINETTI, Horacio. (2006): La Reforma Universitaria (1918-2006), Santa Fe, Universidad Nacional del Litoral, y BIAGINI, H. E. (2000): La Reforma Universitaria: antecedentes y consecuentes, Buenos Aires, Leviatán.
} 


\section{En aras del segundo centenario}

Contrario sensu a lo que suele aducirse, tras el apagón de la llamarada sesentista — autogestionaria e insumisa —, aún durante la misma restauración conservadora y el repliegue posmoderno de los años ochenta y noventa, no dejan de producirse diversas exteriorizaciones políticas con subida presencia adolescente y juvenil: el ascenso del Frente Sandinista de Liberación en Nicaragua, la gestación del Frente Farabundo Martí para la Liberación Nacional en la República del Salvador, el surgimiento del Frente Patriótico Manuel Rodríguez con su guerrilla urbana pugnando en Chile contra el pinochetismo. También se encuentran un sinnúmero de movilizaciones generacionales: contra la corrupción de los presidentes Collor de Melo y Carlos Andrés Pérez - finalmente depuestos - en Brasil y Venezuela, ante la intentona golpista de Lino Oviedo en Paraguay, frente a los fraudulentos intentos reeleccionistas de Fujimori en el Perú o frente a la imposición del estado de sitio en Bolivia. ${ }^{39}$

La raigambre confrontativa de las agrupaciones estudiantiles habrá de renovarse en nuestra América a contrapelo de las políticas neoliberales en distintos terrenos: aumentos tarifarios, crisis económicas, desempleo masivo, recortes presupuestarios; proyectos pedagógicos tecnocráticos, intromisión policial en las universidades, asesinato de alumnos, privatización de la enseñanza, cupos de ingreso, salarios docentes adeudados, y un largo etcétera verificable por doquier. Se trata de acciones que, junto a otras medidas - como las denuncias contra la Cumbre de las Américas, el Tratado de Libre Comercio o las maniobras militares de Estados Unidos — han sido llevadas a cabo únicamente por estudiantes o en operativos conjuntos con otros actores sociales y organizaciones populares. ${ }^{40}$

Por otro lado, el Foro Social Mundial (FSM) originado en Porto Alegre, constituye uno de los cónclaves más multitudinarios de la historia que se ha convertido en el espacio alternativo más relevante frente a la globalización financiera y en una especie de ciudad de ciudades por la paz, tal como lo fue Woodstock en su momento. Allí se ha observado el crecimiento de un nuevo activismo estudiantil que, aunque se autodescriba como fuertemente internacionalista y democrático desde sus orígenes, se mide frontalmente contra el propio paradigma neoconservador. ${ }^{41}$ Dentro de ese foro gaúcho se ha reunido un taller sobre Movimiento Estudiantil y Universidad propuesto por la Organización Continental Latinoamericana y Caribeña de Estudiantes, que fuera publicado por el Centro de Estudiantes de Ciencias Económicas de la

${ }^{39}$ BIAGINI, Hugo E. (1994): La Generación del Ochenta: Cultura y politica, Buenos Aires, Losada. p. 110

BIAGINI, Hugo E. (Compilación). (2000): La Universidad de La Plata y el movimiento estudiantil, La Plata, Universidad Nacional. p. 80

BIAGINI, Hugo E. (2000):Lucha de ideas en Nuestramérica, Buenos Aires, Leviatan. p. 25 
Universidad de Buenos Aires. Sus compiladores trasmitieron la convicción de que en Porto Alegre se pudo vivir una hora de revolución americana similar a la que sintieron los viejos reformistas cordobeses. ${ }^{42}$ En ese taller se pasó revista a las grandes cuestiones en las que se ha involucrado el estudiantado de diversos países: los alumnos ecuatorianos liderando la campaña contra la dolarización de la economía, los nicaragüenses a favor del $6 \%$ constitucional para el presupuesto educativo o los paraguayos empeñados en conquistar un $3 \%$ para la enseñanza superior, junto a tantos otros despliegues de militantes universitarios enfrentándose al statu quo. En ese mismo texto se ha incluido también la declaración final de un congreso latinoamericano de estudiantes celebrado últimamente en la cual se sintetiza el cuadro antes perfilado:

Las combativasjornadas del estudiantado incluyen victorias significativas en muchos paises, dejando en claro que el movimiento estudiantil es capaz de hacer valer sus derechos. En algunospaises las luchas con confrontaciones directas para expulsar del poder a presidentes corruptos y entregnistas; en otros, la jwventud estudiantil reta a sanguinarios tiranos, a paramilitares o a la presencia colonial norteamericana [...] Luchamos por una Nueva Universidad: realmente democrática, autónoma, cientifica, popular y bumanistica. Una Nueva Universidad que contribuya a romper la dependencia científica y tecnológica. ${ }^{43}$

En el FSM se verificó una activa asistencia de miles de jóvenes acampantes, con sus propios canales de expresión y su dinámica peculiar, que llegaron a dialogar en video — conferencia con sus congéneres activistas que se manifestaban simultáneamente durante las reuniones del Foro Económico Mundial para planear acciones comunes de resistencia contra el expansionismo mercadofilico. ${ }^{44}$

En un terreno menos ambicioso pero tal vez más efectivo, la agrupación H.I.J.O.S, sigla de Hijos por la Identidad y la Justicia contra el Olvido y el Silencio, reúne a hijos de desaparecidos, presos políticos u exiliados durante las dictaduras en la Argentina y Sudamérica de los años '70. Su objetivo fundamental consiste en el juicio y castigo a los militares y torturadores que instrumentaron el genocidio y el terrorismo de Estado. Para llevar a cabo sus propósitos, los H.I.J.O.S se valen del Internet, de un periódico propio y del operativo escrache, por el cual se acercan a las residencias de los represores, pintan sus paredes y reparten volantes entre los vecinos para que éstos se enteren de que aquéllos mataron, robaron, violaron o se apropiaron de niños recién nacidos. En ocasiones se han efectuado esos repudios en presencia del periodismo extranjero, interesado en producir sus propios documentales sobre dicha organización juvenil. Se trata de un movimiento que cuenta con respaldo y ramificaciones en

\footnotetext{
${ }^{42}$ Op. cit., p. 50

${ }^{43}$ ROMERO, R. y RUIZ MORENO, R. (2001): (comps.), Movimiento estudiantil

y universidad. Buenos Aires, Economizarte.

${ }^{44}$ BIGAINI, Hugo E. (2000): Entre la identidad y la globalización. Buenos

Aires, Leviatan. p. 35.
} 
distintos países - Suecia, Alemania, Francia o España—-, donde sus miembros son invitados a participar contra los juicios a los violadores de derechos humanos o a impartir charlas en torno a sus finalidades. Pese a diferenciarse de los métodos que emplearon sus padres, no dejan de asemejarse a ellos en su tónica disidente y en ciertos principios básicos. ${ }^{45}$ Según ha comentado Fernando Ainsa para experiencias como las aquí relatadas, estaríamos frente a diferentes utopías realmente vividas, a testimonios en los cuales cabe comprobar por antonomasia esa simbiosis propuesta por Julia Kristeva entre el ser y la rebelión. ${ }^{46}$

El rol de la juventud en esta clase de movimientos reacios a la concentración de poder ofrece un cariz distinto al que combatía en las calles de París, en el Cordobazo o contra la guerra de Vietnam pero que no ha dejado de liderar las movilizaciones ante un mundo como el presente donde todo se remata. ${ }^{47}$ El rasgo distintivo que acompaña el accionar de las nuevas generaciones consiste en su empeño por desligarse de inveterados afanes de dominio, por fomentar relaciones horizontales que favorezcan la autonomía, el consenso y la creatividad. ${ }^{48}$ Tales generaciones asumen dos posturas fundamentales: por un lado, renegar de un sistema que provoca el sufrimiento mundial, mientras se conceptúa como delito imputable la muerte por inanición. Por otra parte, propiciar firmemente la democracia directa y participativa. ${ }^{49}$ Dicha orientación sostiene la legitimidad de la desobediencia civil, junto con las luchas y resistencias locales y globales. La misma revolución deja de ser concebida como mero recambio de dirigentes o de nuevos controles sociales y partidarios, para resignificarse como proceso cotidiano de construcción de una sociedad distinta, por afuera del mercado, a través tanto de redes alternativas supra e intranacionales cuanto de múltiples sectores y ensayos organizadores. ${ }^{50}$

${ }^{45}$ Citado en ESQUIVADA, G. (2001): Hijos de la buena memoria, Rolling Stones, p.

36.

${ }^{46}$ AINSA, F. (1999): La reconstrucción de la utopía, Buenos Aires, Del Sol; KRISTEVA, J. (2000): El porvenir de una revuelta, Barcelona, Seix Barral, p. 32

${ }^{47}$ BIAGINI, Hugo E. (2000)La reforma universitaria: antecedentes y consecuentes.

Buenos Aires: Leviatán, p. 25.

${ }^{48}$ BIAGINI, Hugo E. (2000): Utopías juveniles. De la bohemia al Che, Buenos

Aires, Leviatan, p. 18.

${ }^{49}$ Op. Cit., p. 52.

${ }^{50} \mathrm{He}$ encarado otros planteamientos temáticos paralelos en el artículo "Cambiar el mundo: entre la reforma universitaria y el altermundismo", Utopía y Praxis Latinoamericana (Universidad del Zulia), 33, 2006, pp. 109-119. 


\section{CONCLUSIONES}

Frente a la crisis que experimentan las grandes visiones del mundo y frente al retroceso de las aspiraciones comunitarias, surge la necesidad de pensar una sociedad propensa a introducir relaciones más humanas, democráticas y transparentes.

Esa actitud innovadora — que apunta a neutralizar las injusticias, a mejorar ostensiblemente la calidad de vida y a defender los sectores desfavorecidosha tenido un fuerte predicamento en las juventudes en general, en la latinoamericana en particular y sobre todo en las fracciones estudiantiles desde el movimiento independentista, pasando por el romanticismo, la bohemia y la Reforma Universitaria iniciada orgánicamente en 1918, sin excluir la tranformación generacional de los años sesenta y diversas expresiones de repudio a las políticas excluyentes o autoritarias; expresiones juveniles como las que en otro plano ha sustentado en este Cono Sur el rock nacional y su cancionero.

La magnitud de nuestra Reforma radica en haber sido uno de los primeros grandes movimientos estudiantiles que aportaron un nuevo enfoque sobre la universidad, cuya finalidad última mantiene plena vigencia y ha sido adoptada inadvertidamente por instancias superiores como la propia UNESCO: orientar ética e intelectualmente a nuestras naciones desprotegidas; en suma, contribuir a aliviar los problemas de la gente y el hábitat, hasta erigirse en una auténtica casa de la esperanza para el desarrollo sustentable y equitativo.

Se asiste así a una revitalización de las luchas estudiantiles, de agiornamento de la universidad pública y la recuperación de su poder decisorio en cuanto a recursos y vertientes disciplinares, enlazándose a la vez con el legado y las reivindicaciones antielitistas de 1918, en favor de la cultura latinoamericana y de las aspiraciones sociales.

Hace una centuria, el movimiento estudiantil — durante su Congreso Americano efectuado en Buenos Aires para el Primer Centenario (1910) — ya había advertido que el conocimiento iba a ser la llave del porvenir, algo así como el tránsito del molino a la chimenea y de ésta a la computadora. Un progreso que aún aguarda extenderse a la gran mayoría de la sociedad mundial, en rigor dividida entre infoglobalizantes e infoglobalizados, con la contrastante realidad de que muchos millones de seres humanos no se han podido beneficiar siquiera de relevantes avances e inventos decimonónicos (instrucción pública obligatoria, electricidad, telefonía, vacunación, etc.).

No obstante, emergen hoy en nuestra América distintas expresiones civiles y oficiales desde un horizonte alentador, como aquél por el cual bregaron los jóvenes reformistas mediante una denodada red comunicacional y en procura de la unidad latinoamericana—obrero—indígena estudiantil; un contexto en el que - frente al liberalismo económico, al neoccidentalismo cultural y al 
realismo periférico_- descuellan diversos indicadores aborigenistas y plebeyos, con mayor sentido social, reimplementación de los recursos naturales y grados más profundos de integración regional.

Según percibieron en su momento los gestores del '18, parece que estuviéramos atravesando por una nueva oleada americanista, pisando quizá como ellos un suelo proclive a los cambios en profundidad, para que nuestros propios pobladores acaso dejen de encarnar una de las peores paradojas históricas: la de la miseria en el reinado de la abundancia junto al desconocimiento rampante de la alteridad.

\section{SELECCIÓN BIBLIOGRÁFICA}

ARCINIEGAS, Germán. (1957): El estudiante de la mesa redonda, Buenos Aires, Edhasa.

BIAGINI, Hugo E. (1973): John Lockey la construcción del liberalismo político, Buenos Aires, EUDEBA.

(1989): Cómo fue la generación del 80, Buenos Aires, Plus Ultra.

(1983): Educación y Progreso, Buenos Aires, Ediciones Docencia y Academia de Ciencias.

(1985): Panorama filosófico argentino, Buenos Aires, EUDEBA.

(Compilación). (1985): El movimiento positivista argentino. Buenos Aires: Editorial de Belgrano.

(1989): Filosofía americana e identidad nacional. El conflictivo caso argentino, Buenos Aires, EUDEBA

(Compilación). (1989): Orígenes de la democracia argentina. El trasfondo krausista, Buenos Aires, Legasa Fundación Ebert.

Historia ideológica y poder social, Buenos Aires, Centro Editor de América Latina.

(Compilación). (1993): Redescubriendo un continente. La inteligencia española en el París Americano, Sevilla, Diputación Provincial

(1995): Intelectuales y politicos españoles a comienzos de la inmigración masiva, Buenos Aires, Centro Editor de América Latina

Losada.

(1994): La Generación del Ochenta: Culturay política, Buenos Aires,

(Compilación). (2000): La Universidad de La Plata y el movimiento estudiantil, La Plata, Universidad Nacional,

(2000):Lucha de ideas en Nuestramérica, Buenos Aires, Leviatan, (2000): Entre la identidady la globalización. Buenos Aires: Leviatan, (2000)La reforma universitaria: antecedentes y consecuentes. Buenos Aires: Leviatán. 
Leviatan,

(2000): Utopias juveniles. De la bohemia al Che, Buenos Aires,

(2007): América Latina hacia su segunda independencia.

Memoria y autoafirmación, Buenos Aires, Aguilar et al.

(2008): Diccionario del pensamiento alternativo, Buenos Aires, Biblos.

»El liberalismo lockeano», en Revista Estudios Políticos (Madrid)

194 (1974): 223-231.

»El individualismo estoico en Hegel». Revista de Estudios Políticos (Madrid) 195/196 (1974): 149-163.

»Locke en la Revolución y la cultura estadounidense». Cuadernos de Filosofía (UBA) 24/25 (1976): 95-97.

»Aporte a las bibliografías lockeanas de Hall y Woolhouse»».

Cuadernos de Filosofía (UBA) 24/25 (1976): 99-108.

FRANCOVICH, Guillermo. (1948): Elpensamiento universitario de Charcas, Sucre, Universidad de San Francisco Xavier.

GONZÁLEZ, Julio V. (1929): en La emancipación de la universidad, Buenos Aires, Talleres Gráficos L. J. Rosso.

LANUZA, José Luis. (1926): La universidad y el pueblo, en La Reforma Universitaria, Tomo I, DEL MAZO, G. (comp.), Buenos Aires, FUBA.

MARSISKE, Renate. (1999): Movimientos estudiantiles en la Historia de América Latina, I, México, UNAM.

MELLA J. A. (1959): ¿Puede ser un hecho la reforma universitaria?, en La Reforma Universitaria, 1918-1958, AA.VV., Buenos Aires, Federación Universitaria.

MINUTOLO, Cristina. (1987): El rol de la Universidad de San Francisco Xavier de Chuquisaca en la epopeya emancipadora de América, Buenos Aires, Embajada de la República de Bolivia.

ROCA, Deodoro. (2006): Reformismo y antiimperialismo, Buenos Aires, Grupo Editor Universitario.

TABORDA S. (2007): Reflexiones sobre el ideal politico de América, 2da. edición, Buenos Aires, CECIES y GEU.

VALDÉS V, Carlos. (1918): Evolución y revolución, Juventud (Sgo. de Chile), agosto.

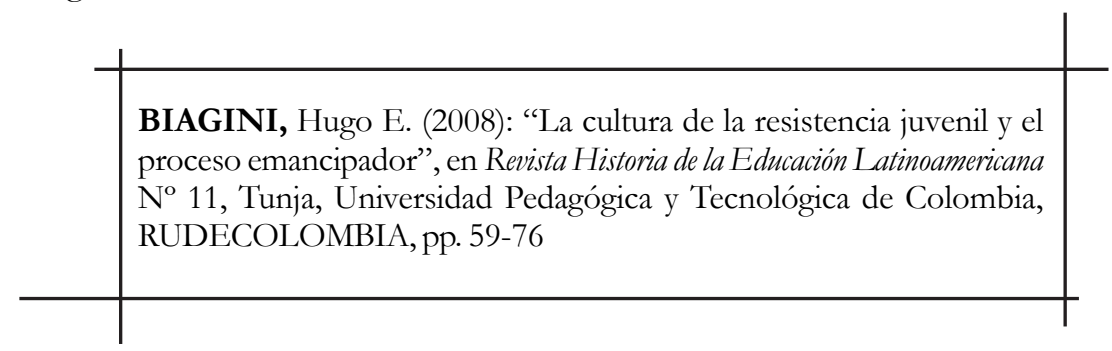

